\title{
Estimation of Metallothionein Synthesis in Cadmium-exposed Human Lymphocytes by Gel Electrophoresis and Silver Staining
}

\author{
Hiroshi JONAI $^{* 1)}$, Hirotomo YAMADA ${ }^{1)}$, Kaoru SUZUKI ${ }^{1)}$, \\ Fuminori OTSUKA $^{2)}$ and Shinji KOIZUMI ${ }^{1)}$ \\ 1) National Institute of Industrial Health, 21-1, Nagao 6-chome, Tama-ku, \\ Kawasaki 214 Japan. \\ 2) Teikyo University, Sagamiko, Kanagawa, 199-01, Japan
}

(Received July 6, 1992 and in revised form September 14, 1992)

\begin{abstract}
Metallothionein (MT) is a low molecular weight metal-binding protein that is induced by a variety of heavy metals, and therefore is a candidate for an index in the biological monitoring of heavy metal exposure. As an approach to the establishment of a practical monitoring method, we estimated the MT levels in Cd-exposed cultures of human peripheral blood mononuclear cells as well as purified lymphocytes using a technique developed for the electrophoretic analysis of MTs. By this procedure, we could successfully detect the MTs induced by $\mathrm{Cd}$ in a dose-dependent manner. MTs were detectable even in cells exposed to as low as $0.5 \mu \mathrm{M} \mathrm{Cd}$, which is close to the blood $\mathrm{Cd}$ levels of exposed workers. These results indicate the usefulness of this technique as a practical method for the monitoring of heavy metal exposure.
\end{abstract}

Key words: Human lymphocyte-Cadmium-Metallothionein-Silver staining-Biological monitoring

\section{INTRODUCTION}

Metallothioneins (MTs) are small proteins that bind heavy metals through their cysteine residues, and are assumed to be involved in heavy metal detoxification as well as essential metal metabolism ${ }^{1)}$. MT synthesis can be induced by various heavy metals such as $\mathrm{Cd}, \mathrm{Zn}, \mathrm{Cu}$ and $\mathrm{Hg}^{2,3)}$, and in a variety of cell types ${ }^{3-5)}$. In our previous studies, it was demonstrated that human peripheral blood lymphocytes also have the ability to synthesize MTs in response to several heavy metals including $\mathrm{Cd}, \mathrm{Zn}, \mathrm{Cu}, \mathrm{Hg}, \mathrm{Ni}$ and $\mathrm{Ag}^{6-9}$. This provides an opportunity to monitor the heavy metal exposure of individual workers, by measuring their lymphocyte MT levels. In the present work, we estimated the MT levels of human lymphocytes exposed to various concentrations of $\mathrm{Cd}$ in vitro, as an approach to the development of a practical monitoring method. For the detection

\footnotetext{
* To whom correspondence should be addressed.
} 
of MTs, we applied sodium dodecyl sulfate (SDS)-gel electrophoresis of chemically modified $\mathrm{MTs}^{10}$ ) and a highly sensitive silver staining method ${ }^{11)}$ that we developed previously. Using this procedure, we could successfully detect the lymphocyte MTs induced by $\mathrm{Cd}$ in a dose-dependent fashion.

\section{Materials AND MethodS}

\section{Chemicals}

Ficoll paque was obtained from Pharmacia, Sweden. All other cell culture reagents were from GIBCO, USA. Cadmium chloride was from Nacalai Tesque Inc., Japan. Iodoacetic acid was from Wako Pure Chemical Industries Ltd., Japan. All other chemicals were of reagent grade.

\section{Culture of lymphocytes}

Twenty $\mathrm{ml}$ of peripheral blood was taken from each of four healthy Japanese, and mononuclear cells were isolated by centrifugation of the blood samples through Ficoll-paque step gradients ${ }^{6}$. The cells were then incubated in $6-\mathrm{cm}$ plastic dishes (Falcon) with growth medium (RPMI 1640 medium supplemented with $10 \%$ fetal calf serum) at $37^{\circ} \mathrm{C}$ for $1 \mathrm{~h}$ to remove adherent monocytes. Lymphocytes were adjusted to $1.2 \times 10^{6} \mathrm{cells} / \mathrm{ml}$ of growth medium containing $100 \mu \mathrm{g}$ of streptomycin $/ \mathrm{ml}$ and 100 units of penicillin $/ \mathrm{ml}$, and cultured in $48-$ well plastic plates $\left(1-\mathrm{ml}\right.$ cell suspension/well) at $37^{\circ} \mathrm{C}$ under a $5 \%-\mathrm{CO}_{2}$ atmosphere.

In the experiment shown in Fig. 3, mononuclear cells were isolated from two healthy Japanese. The cells were cultured as above but were incubated in 6-well plastic plates $(3.5-\mathrm{ml}$ cell suspension/well).

\section{Estimation of viability}

A cell suspension $(30 \mu 1)$ was mixed with $6 \mu 1$ of $0.4 \%$ trypan blue solution and allowed to stand for $5 \mathrm{~min}$ at room temperature. The number of stained cells and the total number of cells were counted.

\section{Preparation of cell extracts}

Cell extracts were prepared essentially as described previously ${ }^{5)}$. The cells in each well were collected by centrifugation and washed three times with ice-cold PBS(-) (Dulbecco's phosphate buffered saline without $\mathrm{Mg}^{2+}$ and $\mathrm{Ca}^{2+}$ ). The cell pellet was resuspended in $20 \mu 1$ (or $35 \mu 1$ for the cultures in 6-well plates) of ice-cold lysis buffer (100 mM Tris- $\mathrm{HCl}$, pH 7.5/0.15M NaCl/3 mM $\mathrm{MgCl}_{2} / 0.5 \%$ Nonidet $\mathrm{P}-40$ ), and left for $5 \mathrm{~min}$ at $0{ }^{\circ} \mathrm{C}$. The lysate was centrifuged at 12,000 $\mathrm{xg}$ for $5 \mathrm{~min}$ at $4{ }^{\circ} \mathrm{C}$. The supernatant was carboxymethylated as described ${ }^{10)}$, with slight modifications. Ten $\mu 1$ of the supernatant was mixed with $5 \mu 1$ of a solution containing $0.2 \mathrm{M}$ Tris- $\mathrm{HCl}, \mathrm{pH} 8.8,8 \%$ SDS and 50\% glycerol, $1 \mu 1$ of $0.4 \mathrm{M}$ 
dithioerythritol and $1 \mu \mathrm{l}$ of $0.4 \mathrm{M}$ ethylenediaminetetraacetic acid, and boiled for $5 \mathrm{~min}$. After the sample was cooled to room temperature, $3 \mu 1$ of a recrystallized iodoacetic acid solution (a $1 \mathrm{M}$ solution adjusted to $\mathrm{pH} 8$ with $\mathrm{NaOH}$ just prior to use) was added, and the mixture was incubated at $50{ }^{\circ} \mathrm{C}$ for $15 \mathrm{~min}$. The sample was cooled to room temperature, and mixed with $2 \mu 1$ of $0.3 \%$ bromophenol blue for electrophoresis. For the experiment shown in Fig. $2 \mathrm{~b}$, the cell extracts were centrifuged through a C3TK ultrafilter (Millipore) at $4,000 \mathrm{xg}$ for $20 \mathrm{~min}$ just prior to electrophoresis, to minimize background interference in the low molecular weight range.

\section{SDS-gel electrophoresis}

Polyacrylamide gel and the electrode buffer were prepared according to the method of Laemmli ${ }^{12}$, with $15 \%$ separating gel (3\% cross-linking; 1-mm thick). The gel was run at $30 \mathrm{~mA}$ for $4 \mathrm{~h}$ in an apparatus in which the gel plate is directly cooled by the upper electrode buffer (ATTO, Japan). The purified rat MT- I and MT-II used as references were the generous gifts of Dr. N. Otaki.

\section{Silver staining}

Proteins on the gel were silver-stained essentially according to Otsuka et al. ${ }^{11)}$, with slight modifications. All solutions were made with distilled and deionized water. In every step described below, the gel was treated with $200 \mathrm{ml}$ of the solutions with gentle shaking at $30^{\circ} \mathrm{C}$. (1) The gel was stained with a dye solution containing $0.25 \%$ coomasie brilliant blue, 50\% methanol and $12.5 \%$ trichloroacetic acid (TCA) for $5 \mathrm{~min}$, (2) destained in 40\% methanol and 12.5\% TCA for $15 \mathrm{~min}$ twice, (3) soaked in $40 \%$ methanol and $10 \%$ acetic acid for 15 min twice, (4) soaked in $10 \%$ ethanol and 5\% acetic acid for 15 min twice, (5) washed with water for $10 \mathrm{~min}$ twice, (6) soaked in $1 \%$ sodium thiosulfate for 5 min, (7) washed with water for $5 \mathrm{~min}$ twice, (8) soaked in $3.2 \mathrm{mM}$ potassium dichromate and $3.2 \mathrm{mM}$ nitric acid for $10 \mathrm{~min}$, (9) washed with water for $5 \mathrm{~min}$ twice, (10) soaked in $0.2 \%$ silver nitrate for $20 \mathrm{~min}$, and (11) washed with water for $1 \mathrm{~min}$ twice. (12) The gel was treated with $0.28 \mathrm{M}$ sodium carbonate and $0.0185 \%$ formaldehyde until a desired image was obtained. (13) The reaction was stopped by soaking the gel in 5\% acetic acid for 5 min twice. (14) The gel was washed with water for $5 \mathrm{~min}$ twice.

\section{RESULTS}

\section{Cytotoxicity of $\mathrm{Cd}$ to human lymphocytes}

To estimate the cytotoxic effects of $\mathrm{Cd}$ on the isolated lymphocytes, the changes in cell viability during incubation with or without $\mathrm{Cd}$ were determined (Fig. 1). The unexposed cells had a viability of greater than $90 \%$ even after $5^{\circ} \mathrm{d}$ 

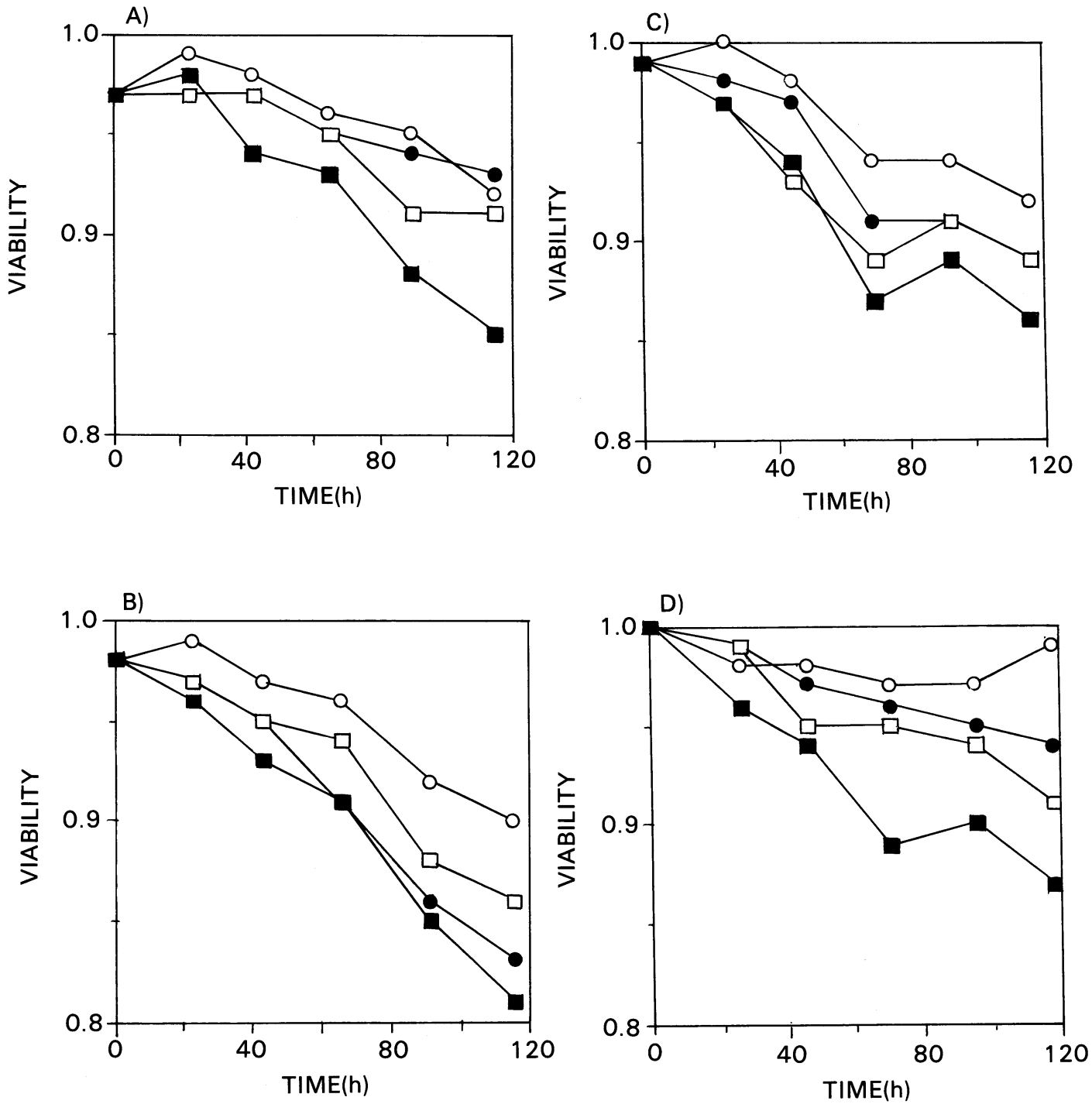

Fig. 1. Viability of lymphocytes cultured with or without Cd. Lymphocytes isolated from 4 individuals (A, 33-year-old female; B-D, 24-, 28-, and 43-year-old males, respectively) were cultured with $\mathrm{O}(\bigcirc), \mathbf{5}(\bigcirc), \mathbf{1 0}(\square)$ or 20 ( $\square) \mu \mathrm{M} \mathrm{CdCl}_{2}$ for 5 d. Cell viability was determined at the indicated time points by trypan blue dye exclusion test in duplicate.

of culture. This was true for all the lymphocytes isolated from the four donors. There were apparent differences in the viability of lymphocytes between individuals; for example, more than $97 \%$ of the lymphocytes from donor D were viable during the incubationl period, whereas the viability of cells from donor $B$ was reduced to approximately $90 \%$ at the 5 th day. We observed distinct cytotoxic effects of $\mathrm{Cd}$ on the viability of lymphocytes, but the effects were moderate: 


\section{A}

(a)

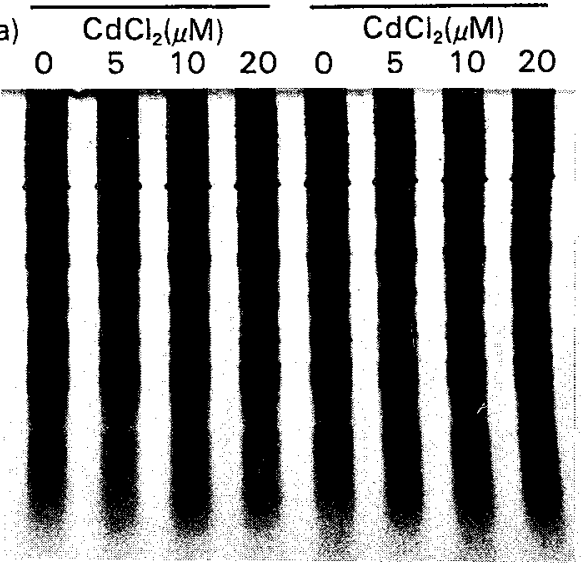

B

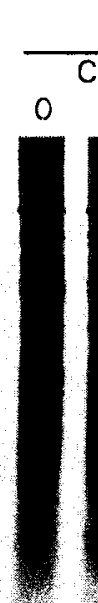

\section{C} $(\mu \mathrm{M})$

$\begin{array}{lll}5 & 10 \quad 20\end{array}$

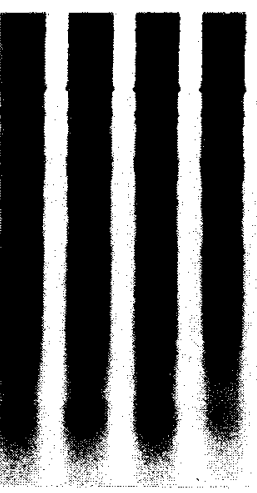

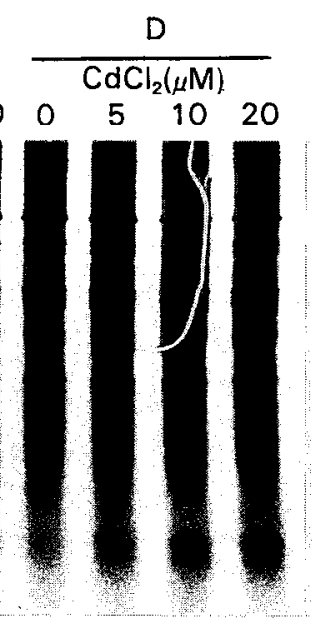

- MTI

(b)
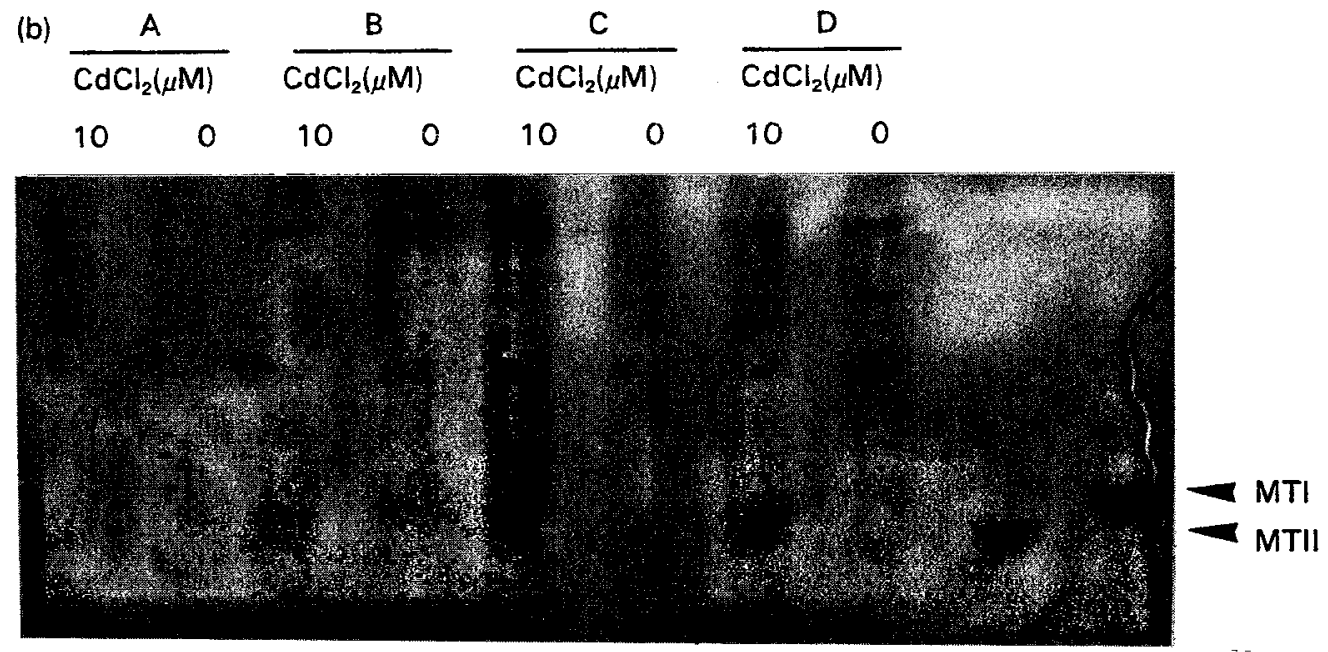

Fig. 2. Detection of Cd-induced lymphocyte Mrs by silver staining. extracts were prepared from the 5-d cultures of the lymphocytes derived from donors A-D shown in Fig. 1 (i. e. from all the rest of the lymphocytes after cell counting). (a) The carboxymethylated proteins (22 $\mu \mathrm{l}$ each) were electrophoresed in SDS-15\% polyacrylamide gel and detected by silver staining. Electrophoresis of purified rat MT- I and MT-II is also shown on the right. The left half ( $A$ and $B$ ) and the right half (C and D) were electrophoresed separately. (b) The carboxymethylated extracts of the lymphocytes from donors $A-D$ exposed to 0 or $10 \mu \mathrm{M}$ Cd were filtered through a C3TK filter. These samples (12 $\mu \mathrm{l}$ each) as well as purified rat MTs were electrophoresed in the same gel, and the proteins were detected by silver staining.

$81-87 \%$ of the cells were still viable after the $5-\mathrm{d}$ incubation period even in the presence of $20 \mu \mathrm{M} \mathrm{Cd}$. There were no significant differences between individuals in the cytotoxicity index (viable cells in the Cd-exposed culture/viable cells in the control unexposed culture). 


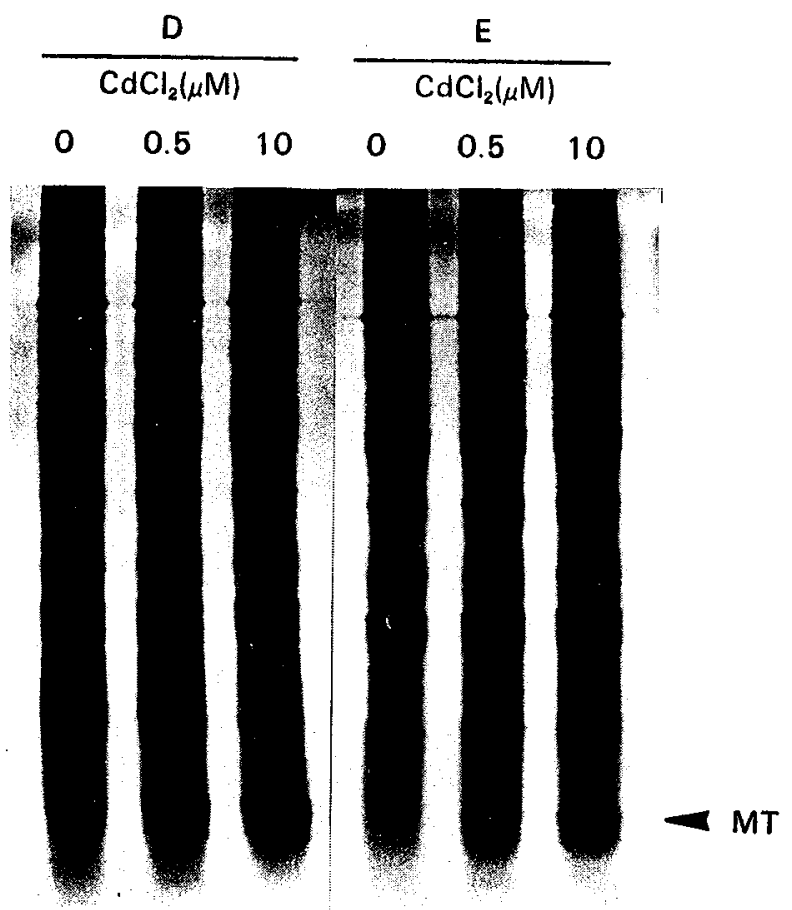

Fig. 3. Detection of MTs in mononuclear cells exposed to a low concentration of $\mathrm{Cd}$. The mononuclear cells isolated from two individuals (D, 43-year-old male; E, 42-year-old female) were cultured in the presence of $0,0.5$ or $10 \mu \mathrm{M} \mathrm{CdC1}_{2}$ for 5 d. The carboxymethylated extracts (11 $\mu \mathrm{l}$ each) were electrophoresed as in Fig. 2a, and the proteins were detected by silver staining.

\section{$M T$ induction in Cd-exposed lymphocytes}

We analyzed the extracts of Cd-exposed lymphocytes by a method developed for the measurement of MTs. This procedure involves denaturing electrophoresis of MTs, the cysteine residues of which were carboxymethylated to avoid the formation of intermolecular S-S linkages ${ }^{10)}$, and a highly sensitive silver staining method specially modified for the detection of carboxymethylated MT derivatives $^{11)}$. Cd-induced synthesis of MTs was clearly detected in all the lymphocytes from the four donors (Fig. 2a). These induced MT levels were observed to increase with elevated concentrations of $\mathrm{Cd}$. Both of the major MT isoforms, MT-I and MT-II, were induced, and in all of the cells, the MT-I isoform was produced more abundantly than the MT-II isoform. The levels of MTs induced did not appear to be identical between individuals. To show the differences unambiguously, extracts of the lymphocytes from the four donors were directly compared on the same gel (Fig. 2b). The results indicated that there are 
obvious differences between individuals in the ability to synthesize MTs in response to an identical concentration of $\mathrm{Cd}$. The lymphocytes from donor $\mathrm{D}$ synthesized MTs most abundantly, whereas those from donor A synthesized only a small amount. We found no significant relationship between the ability to synthesize MTs and cell viability (Fig. 1).

\section{Detection of MTs induced by a low concentration of Cd}

For practical use, it is important to know whether this technique can be used for the detection of MTs induced by a concentration of $\mathrm{Cd}$ as low as that in the blood of Cd-exposed humans. We therefore analyzed the extracts of mononuclear cells (containing both lymphocytes and monocytes) exposed for $5 \mathrm{~d}$ to $0.5 \mu \mathrm{M}$ $\mathrm{Cd}$, which is close to the actual $\mathrm{Cd}$ level in the blood of Cd-exposed workers ${ }^{13)}$. The use of a mononuclear cell preparation instead of purified lymphocytes was expected to be effective in increasing the sensitivity of detection, by minimizing the loss of lymphocytes and including monocytes which have also been demonstrated to synthesize MTs in response to $\mathrm{Cd}^{6)}$. As shown in Fig. 3, the induction of MTs was detectable even at a Cd concentration of $0.5 \mu \mathrm{M}$, suggesting that this technique will be useful in the practical monitoring of MT levels induced by heavy metal exposure in vivo.

\section{Discussion}

MTs are induced in response to a variety of stimuli, including heavy metals, mainly in the liver and kidney ${ }^{1)}$. Our previous findings that peripheral blood lymphocytes also have the ability to synthesize MTs in response to various heavy metals ${ }^{6-9)}$ suggested that the heavy metal exposure of humans could be monitored by measuring the MT levels in lymphocytes, which are easily isolated from the human body. However, there has been no convenient procedure that would enable the practical use of lymphocyte MTs as a monitoring index. One of the most promising methods is electrophoresis of carboxymethylated MTs, which has the following advantages. 1)Carboxymethylation makes an MT molecule to be detected as a discrete single band by preventing aggregation. 2)The carboxymethylated monomer MT polypeptides migrate faster than the bulk of cellular proteins, which enables the estimation of MT levels by the direct analysis of crude cell extracts. 3)A number of samples can be analyzed simultaneously. A problem was the lack of an appropriate method for the detection of carboxymethylated MTs; the detection of radiolabeled cellular proteins is a sensitive method, but it is largely impractical for the direct determination of MT levels in lymphocytes exposed to heavy metals in vivo, and the conventional dye staining of proteins, for example with coomasie brilliant blue or amido black, is not sensitive enough to detect MTs in crude cell extracts. Highly sensitive silver staining ${ }^{14)}$ appeared to be most suitable for this purpose, but it was also problematic, since 
carboxymethylated MTs are negatively stained by this technique ${ }^{11)}$. However, we circumvented this difficulty by modifying conventional silver staining, making highly sensitive detection of carboxymethylated MTs possible ${ }^{11)}$.

Using these techniques, we successfully detected Cd-induced MTs in cultured human mononuclear cells as well as purified lymphocytes. MTs are detectable in cells exposed to as low as $0.5 \mu \mathrm{M} \mathrm{Cd}$, near the level in the blood of Cd-exposed workers $^{13)}$, and electrophoresis of an extract equivalent to only a few $\mathrm{ml}$ of blood is sufficient for the detection of MTs. These results indicate that the present technique will be useful in the practical monitoring of heavy metal exposure in workers. Background interference in the low molecular weight region of the gel is a problem, because it makes the MT bands unclear. Several pretreatments of cell extracts have been found to be effective in removing this interference ${ }^{11)}$. Filtration of extracts prior to electrophoresis, which is one of these procedures, improved the signal/noise ratio in the MT region (see Fig. 2b).

Our electrophoretic technique can separate the major MT isoforms, MT-I and MT-II, from each other (see Figs. 2 and 3). This will be advantageous in predicting the stimulus to which the lymphocytes have been exposed, since different stimuli often induce different patterns of isoforms ${ }^{15,16)}$. Differential expression of the MT isoforms has also been observed in different types of cells ${ }^{16-18)}$. In human lymphocytes, the MT-I isoform is preferentially synthesized in response to $\mathrm{Cd}$ (Fig. 2), while the MT-II isoform is the major product in Cd-exposed Hela cells derived from human cervical carcinoma ${ }^{5}$. It is unclear what this difference means.

There are apparent differences in the levels of Cd-induced MTs between lymphocytes isolated from different donors. This is undesirable for practical biological monitoring, since it is difficult to predict the absolute exposure levels of individual workers from the measurement of their MTs. To make the monitoring significant, it may be necessary to follow time-dependent changes in the MT level, as well as to know the control MT value in the absence of heavy metal exposure. On the other hand, the individual differences in MT response appear to be applicable to the estimation of the sensitivity of workers to heavy metals, since the ability to synthesize MTs correlates genetically with resistance to $\mathrm{Cd}^{19-21)}$. Prior determination of heavy metal-induced lymphocyte MT levels can therefore predict a high risk group in a working place where possible heavy metal exposure is expected, and the exclusion of such workers would be an effective way to prevent the occurrence of heavy metal intoxication. Further development of practical methods of these applications are now under investigation.

\section{ACKNOWLEDGMENT}

We thank Dr. N. Otaki for providing purified rat MT-I and MT-II. 


\section{REFERENCES}

1) Kägi JHR, Kojima Y. Metallothionein II. Basel: Birkhäuser, 1987.

2) Durnam DM, Palmiter RD. Transcriptional regulation of the mouse metallothionein-I gene by heavy metals. J. Biol. Chem. 1981; 256: 5712-6.

3) Koizumi S, Sone T, kimura M. Induction of metallothionein synthesis in cultured cells derived from rabbit kidney. J. Cell. Physiol. 1985; 125 : 223-8.

4) Hidalgo HA, Koppa V, Bryan SE. Induction of cadmium-thionein in isolated rat liver cells. Biochem. J. 1978; 170: 219-25.

5) Koizumi S, Sone T, Otaki N, Kimura M. $\mathrm{Cd}^{2+}$-induced synthesis of metallothionein in $\mathrm{HeLa}$ cells. Biochem. J. 1985; $227: 879-86$.

6) Sone T, Koizumi S, Kimura M. Cadmium-induced synthesis of metallothioneins in human lymphocytes and monocytes. Chem.-Biol. Interact. 1988; 66: 61-70.

7) Koizumi S, Sone T, Kimura M, Otsuka F, Ohsawa M. Metallothioneins of monocytes and lymphocytes. In: Kägi JHR, Kojima Y, eds. Metallothionein II. Basel: Birkhäuser, 1987; 519-23.

8) Yamada H, Minoshima S, Koizumi S, Kimura M, Shimizu N. Cadmium-induced synthesis of metallothioneins in human $\mathbf{T}$ and $\mathbf{B}$ cell purified by a fluorescence activated cell sorter. Chem. -Biol. Interact. 1989; 70: 117-26.

9) Yamada H, Koizumi S. Metallothionein induction in human peripheral blood lymphocytes by heavy metals. Chem.-Biol. Interact. 1991; 78: 347-54.

10) Koizumi S, Otaki N, Kimura M. Estimation of thionein synthesis in cultured cells by slab gel electrophoresis. Ind. Health 1982; 20: 101-8.

11)Otsuka F, Koizumi S, Kimura M, Ohsawa M. Silver staining for carboxymethylated metallothioneins in polyacrylamide gels. Anal. Biochem. 1988: 168: 184-92.

12) Laemmli UK. Cleavage of structural proteins during the assembly of the head of bacteriophage T4. Nature 1970; 227: 680-5.

13)Kjellström T, Nordberg GF. A kinetic model of cadmium metabolism in the human being. Environ, Res. 1978: 16: 248-69.

14) Merril CR, Goldman D, Sedman S, Ebert MH. Ultrasensitive stain for proteins in polyacrylamide gels shows regional variation in cerebrospinal fluid proteins. Science $1981 ; 211: 1437-8$.

15) Richards RI, Heguy A, Karin M. Structural and functional analysis of the human metallothionein- $\mathrm{I}_{\mathbf{A}}$ gene: differential induction by metal ions and glucocorticoids. Cell 1984; 37 : 263-72.

16) Schmidt CJ, Hamer DH. Cell specificity and an effect of ras on human metallothionein gene expression. Proc. Natl. Acad. Sci. USA 1986; 83: 3346-50.

17) Heguy A,West A, Richards RI, Karin M. Structure and tissue-specific expression of the human metallothionein $I_{B}$ gene. Mol. Cell. Biol. 1986; 6: 2149-57.

18) Jahroudi N, Foster R, Price-haughey J, Beitel G, Gedamu L. Cell-type specific and differential regulation of the human metallothionein genes: correlation with DNA methylation and chromatin structure. J. Biol. Chem. 1990; 265 : 6506-11.

19) Tsunoo H, Nakajima H, Hata A, Kimura $M$. Genetic influence on induction of metallothionein and mortality from cadmium intoxication. Toxicol. Lett. 1979; 4: 253-6.

20) Piletz JE, Andersen RD, Berry W, Herschman HR. Synthesis and degradation of hepatic metallothionein in mice differing in susceptibility to cadmium mortality. Biochem. Genet. 1983; 21: 561-78.

21) Rugstad HE, Norseth $T$. Cadmium resistance and content of cadmium-binding protein in cultured human cells. Nature $1975 ; 257: 136-7$. 